Advancing quantitative rigor in the circular economy literature: New methodology for product lifetime extension business models

Myriam Ertz $^{\mathrm{a} *}$, Sébastien Leblanc-Proulx ${ }^{\mathrm{b}}$, Emine Sarigöllï̈ ${ }^{\mathrm{c}}$, Vincent Morin $^{\mathrm{d}}$

*Corresponding author

aLaboNFC, Université du Québec à Chicoutimi, Chicoutimi, QC, Canada

555, Boulevard de 1’Université, Chicoutimi, Québec, G7H 2B1, Canada, E-mail : Myriam_Ertz@uqac.ca, Phone : +1-418-545-5011

b LaboNFC, Université du Québec à Chicoutimi, Chicoutimi, QC, Canada 555, Boulevard de 1'Université, Chicoutimi, Québec, G7H 2B1, Canada, E-mail : Sebastien_Leblanc-Proulx@uqac.ca, Phone : +1-418-545-5011

${ }^{\mathrm{c}}$ LaboNFC, Desautels Faculty of Management, McGill University, Montreal, QC, Canada

1001, Rue Sherbrooke Ouest, Québec, H3A 1G5, Canada

E-mail: emine.sarigollu@mcgill.ca, Phone : +1-514-398-4000

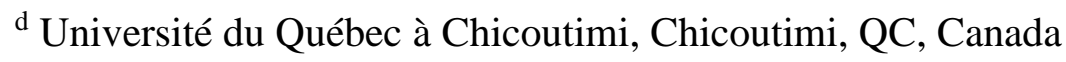
555, Boulevard de 1'Université, Chicoutimi, Québec, G7H 2B1, Canada, E-mail : Vincent_Morin@uqac.ca, Phone : +1-418-545-5011 


\title{
Advancing quantitative rigor in the circular economy literature: New methodology for product lifetime extension business models
}

\begin{abstract}
Research on product lifetime extension (PLE) is of emerging interest in the circular economy (CE), but the extant literature is deficient in various aspects. First, it lacks a systematic analysis of the structure which underlies organizational efforts to PLE. Second, the literature has overlooked the role of two key agents in circular economy, namely, businesses and consumers. Third, the literature lacks a systematic study of the product lifetime extension strategies. Fourth, although several studies have proposed taxonomies of organizations in the circular economy, they lack quantitative rigor, ecological validity, and generalizability. The purpose of this study is to address these deficiencies in the circular economy literature. Specifically, this article develops and empirically validates a methodology to classify a specific type of circular business model, namely product lifetime extension business models, involving organizations and consumers, to bring quantitative rigor to conduct and presentation of taxonomy research in the field of the circular economy.
\end{abstract}

Keywords: quantitative rigor, taxonomy, classification, circular economy, business model, product lifetime extension.

\section{Introduction}

Municipal waste is expected to increase to 2.2 billion tonnes by 2025 (World Bank, 2018). This surge in waste results from the disposal of physical products, causing serious environmental threats in many parts of the world (World Bank, 2018). Circular Economy (hereafter, CE) has been proposed as a system to curb the serious threats caused by the increase in waste.

The increase in solid waste from physical products results mainly from organizations and consumers. Yet, consumers have not received much attention in the $\mathrm{CE}$ literature, despite the crucial role they play in increasing waste through their consumption and disposal behaviors. In 
fact, CE studies mainly take a managerial perspective without considering what could be done to better integrate the consumer in the CE loop. For example, Kirchherr et al. (2017) comment that we do not know much about how consumers currently fit in the CE and what more they could possibly do to better enact the $\mathrm{CE}$. Yet, the CE not only requires innovative concepts but also innovative actors, and transition towards CE comes from involvement of all actors of the society and their capacity to link and create suitable collaboration and exchange patterns (Ghisellini et al., 2016). Upholding this view, this article explicitly involves consumers and organizations as actors in CE.

Physical products constitute an important part of the overall amount of solid waste. As such, if their lifetimes could be extended, solid waste formation could be curbed. In this study, product lifetime (hereafter, PL), is defined as the useful life of a product. This means, the period during which a product remains integer and reusable to execute the main function for which it was originally manufactured (Cooper, 2010). The methodology presented in this article takes this specific definition as the point of reference. Furthermore, this article makes four contributions to research on CE by explicitly addressing various gaps in the current literature, specifically, lack of focus on product lifetime extension (hereafter, PLE) practices in the CE literature; neglect of the consumer's role; absence of systematic analysis of organizational structure using formal business modelling; and lack of attention to PLE typologies, in contrast to CE typologies.

First, this article advances research on product lifetime extension (hereafter, PLE) which is an area of emerging interest in the CE literature (Khan et al., 2018; Nußholz, 2018). PLE refers to different approaches for extending the useful life of a product through improved design as well as maintenance and prolonged usage. Importantly, the product needs to remain integer and usable for the main function for which it was originally conceived and manufactured (Cooper, 2010). 
As waste remains unfortunately prevalent in our societies, PLE strategies such as, take-back programmes, redistribution, remanufacturing, reuse or improved design, become alternatives to landfill, thus require more research attention. This study broadens existing knowledge on PLE by identifying the structure, which underlies organizational efforts to PLE.

Second, past research investigates the CE mainly from a corporate-centric perspective (Kirchherr et al., 2017), and "focused on technological or systems optimization" (Babbitt et al., 2018, p. 2). However, a successful transition toward CE with reuse at its core is highly contingent upon consumers' responsibility, awareness, as well as their collaboration, perceptions, preferences and exchange patterns (Hazen et al., 2017). The consumers play thus a prominent role in PLE. Drawing on the rich literature in marketing, consumer behavior, sociology and anthropology, this study integrates the consumer as a relevant exchange agent and maps the consumer's involvement through $\mathrm{C} 2 \mathrm{C}$ exchange schemes as well as $\mathrm{C} 2 \mathrm{~B} / \mathrm{B} 2 \mathrm{C}$ ones (i.e., buyback, refurbishing).

Third, organizational structures are typically complex, but are even more complex in the case of $\mathrm{CE}$ as organizations seek to operate cradle-to-cradle processes to ensure minimal waste in design, production, delivery and return. Formal frameworks may facilitate systematic analysis of complexity and this study advances the literature by using the business model canvas as the theoretical framework for the proposed methodology. Capitalizing on the extensive business model literature, especially Chesbrough and Rosenbloom (2002), and Osterwalder and Pigneur (2010), this article classifies organizations according to their PLE activities and their key partners.

Fourth, several studies have proposed taxonomies and typologies of organizations in the CE. However, up until now these typologies have been based on qualitative inquiry and lack quantitative rigor, ecological validity, and generalizability. Past research efforts will greatly benefit from enhanced rigor to improve testability and generalizability of their outcomes and this study aims to contribute toward that end. This study proposes and empirically validates a 
systematic, inductive and quantitatively-oriented methodology to develop a taxonomy of product lifetime extension business models (hereafter, PLEBM). PLEBM are business configurations encompassing specific activities aimed at extending product lifetime. The proposed methodology provides additional rigor to the field, enabling researchers to systematically describe and quantitatively derive a classification of organizations in a taxonomy, around certain characteristics, using the business model framework as a theoretical foundation.

The methodology presented in this article pursues the following research questions: How to imbue a taxonomy with quantitative rigor while retaining the explanatory potential for mapping new or existing PLEBM? How to apply systematic and analytical business modelling for a credible representation of the variety of business configurations observed in the CE as well as developing them into a classification that is compelling, defendable and plausible? How to relate the consumer to organizational PLE strategies? The current study addresses these perennial challenges for researchers who seek to advance the understanding of PLEBM and offer a clear mapping of these models. As such, this study responds to the call for novel methods and models, which is a key element in the "closed loop" research model proposed by Babbitt et al. (2018, p. 2), so as to realize the promise of the CE. The closed loop research model stipulates that, "theoretical concepts and fundamental advances are translated into applications in business, policy, and industry, and subsequently assessed to derive research questions.” (p. 2).

To the best of the authors' knowledge, this is the first taxonomical methodology proposed for the classification of PLEBM. The new taxonomy is meant for the use of scholars, institutional researchers, consultants and practitioners who work in the increasingly crucial domain of PLE. The PLEBM taxonomy will enable them to conduct a systematic and comparative analysis of different PLEBM to help identify groups of organizations with similar business models as well as their relative importance in comparison to other groups. Besides, the methodology will allow organizations and scholars to better identify the business models, which characterize organizations that consider PLE as an important process of value creation. Finally, by providing a 
rigorous taxonomy, the methodology enables to create reference points for future research concerning the importance, success and evolution of different types of PLEBM.

The second section of the paper motivates the proposed methodology by introducing the notions of PLE, business models, and emphasizing the need for quantitative rigor. Afterwards, section three elaborates on PL, PLE, and the CE, while section 4 delves deeper into business models. Section 5 presents the methodology, section 6 is an empirical implementation of the proposed methodology and section 7 discusses the results of the empirical analysis, while section 8 outlines the theoretical and managerial implications of the research and provides a reflection upon the future uses of the methodology. Finally, section 9 outlines the limitations and future research avenues of this study.

\section{Motivation for the proposed methodology}

\subsection{Reshaping our views on product lifetime extension}

Past research has devoted precious attention to the ways and means through which PL may be extended, i.e. PLE. However, the main focus of these studies lies on the broader concept of the CE, within which PLE strategies coexist along with other circular strategies such as "substituting existing with renewable and natural processes" (e.g., zero emissions initiatives) (Bocken et al., 2014, p. 48), among many others as in the ReSOLVE framework of The Ellen MacArthur Foundation (2017), for example. Consequently, in all classificatory works of circular business models, PLE activities and strategies are scattered across the proposed taxonomies, rendering a systematic identification, gathering and comparison of PLE business models rather difficult. In short, despite the crucial need for a better understanding of the business types which extend PL, as pointed out in studies on the CE which pinpoint PLE strategies as a core element (for e.g., Khan et al., 2018), a specific focus and classification of PLE business schemes is yet to advance. This study is exclusively focused on the study of PLE.

\subsection{The acknowledgement of the consumer}


Another impetus for developing the approach presented in this study is the recognition that in the field of the CE, most studies are often designed and executed from a corporate-centric viewpoint (Babbitt et al., 2018). This venerable orientation, however, trains our attention to refining of corporate systems and processes, but overlooks the consumers' role. Some studies have started to acknowledge consumers as fundamental enablers of $\mathrm{CE}$ and provided strategies to instill, identify and encourage "pro-circular behaviors" in consumers and organizations (Muranko et al., 2018; Whalen et al., 2018). Yet, such endeavours are not commonplace within the emerging area of PLE. Given the rapid pace at which exchange schemes involving consumers increase, most notably through collaborative economy (e.g. Belk, 2014; PwC, 2015; Ertz et al., 2017c) and product multiple lives practices (e.g. Ertz et al., 2017a, 2017b), consumers require consideration as relevant agents in any serious PLE classification attempt, because of their proclivity to pro-PLE behaviors, as a subset of pro-circular behaviors.

This study seeks to fill that gap by taking the consumer into consideration. In fact, many consumers actively take part in PLE through flea markets, garage sales, antique collection, auctions, secondhand stores, charities, donation centers, swap meets (Ertz et al., 2017a, 2017b) as well as in corporate processes such as reverse logistics, improved product design, take-back/buyback programs, rebuy/recommerce systems, and refurbished, remanufactured, reconditioned or repackaged products (Nussholz, 2017b). For example, Best Buy Canada’s buy-back program enables consumers to trade in their used electronics for gift cards or vouchers. The product is then refurbished and/or repackaged and resold in-store ${ }^{1}$.

\subsection{Making the case for the business model perspective}

Several streams of literature, particularly the CE, demonstrate a great variety of processes and schemes through which PL get extended (e.g. Whalen, 2017). To make practical sense of this complex reality, researchers resorted to systematic analysis through adoption of the business

\footnotetext{
${ }^{1}$ https://www.bestbuy.ca/en-CA/trade-in-program.aspx. (accessed 6-10-2018).
} 
model framework (Manninen et al., 2018). For example, Lüdeke-Freund et al (2018) classify different circular business models including PLE strategies. Bakker et al. (2014) created a 'Products that Last' categorisation as part of the CE focusing on extending the life of products. Bocken and Short (2016) and Bocken et al. (2016) created a sufficiency business model category as part of the $\mathrm{CE}$ strategy focusing on slower consumption e.g. by making products that last, arguably also a PLE strategy. Whalen (2017) created a list of circular business models including 'extending product value' and different company cases. Urbinati et al. (2017) also developed a list of circular business models. However, the business model framework has not been typically delineated as enabler of the CE in general, and even less of PLE, in particular (Kirchherr et al., 2017). The only exception may be Nußholz (2018) who developed a circular business model mapping tool for businesses to create value through closed material loops as well as prolonged PL. Yet, the tool remains focused on the mapping of circular business models in general, but not on PLEBM, in particular. This study adopts the business model framework to study PLE, through what we name a product lifetime business model (PLEBM), incorporating both corporations and consumers as key partners.

\subsection{The need for quantitative rigor}

Most if not all of the studies devoted to the CE, in general, or the few centered on PLE, in particular, adopt a qualitative or conceptual approach to classification (e.g., Whalen, 2017; Gaiardelli et al., 2014; Urbinati et al., 2017; Bocken et al., 2014). Although classification of organizations via elaboration, deduction and conceptual work has served researchers well in the short history of the CE field, their lack of quantitative rigor and generalizability hinder our ability to gain deeper understanding of PLE organization types. For this reason, we believe that an excessive focus on the refinement of existing classifications of circular business models may amount to sharpening of inappropriate tools for gaining bona fide understandings.

What the CE research field and the PLE stream need instead are new tools and new concepts. This requires an approach that provides adequate scientific theorizing about both the consumer 
and the organization levels. In order to accomplish these objectives, we propose a systematic, inductive and quantitatively-oriented approach to PLEBM taxonomy development. Classically, there has been a strong social scientific tradition of using qualitative data to inductively develop "grounded theory" (e.g. Lincoln and Guba, 1985; Gioia et al., 2012). Although some scholars advance that inductive approaches may not meet the standards for demonstrating scientific advancement (e.g. Popper, 1959/2002), we contend that the replacement of qualitative data by quantitative ones will be a means to mitigate that drawback. Second, our quantitative analytical approach relying on formal statistical procedures, assumptions and distributions will further make up for inductivity. Finally, with the growing trend toward Big Data or Large-Scale Data which, by definition, call for inductive approaches (Erevelles et al., 2016), our procedure provides a primer for researchers on how to analyze increasingly larger sets of valuable information about organizations, business models, and PLEBM in particular.

\section{Product lifetime, product lifetime extension and the circular economy}

The proposed methodology is built on several concepts pertaining to the CE. This section introduces these key concepts on which the methodology draws.

PL is different from the "economic life" of a product, which refers to the moment at which the maintenance of a product costs more than its replacement (Heiskanen, 1996). The PL differs also from the "technical life" of a product, which is the maximum period during which a product has the physical capacity to function (Cooper, 2010). This definition conflates with the notion of "functional life" of a product, which is the time that a product should last independently from an external intervention in order to increase its lifetime (Cox et al., 2013).

PL is determined by both technical characteristics and functionalities as well as actions and practices improving those functionalities to extend that product's life (Cox et al., 2013; Bakker et al., 2014). PLE can thus be defined as the use of different approaches to improve the useful life of a product due to design (functional life), as well as, the maintenance and prolonged usage (actions 
taken by different actors). Importantly, the product needs to remain integer and usable for the main function for which it was originally conceived and manufactured (Cooper, 2010).

The CE has been acknowledged as a sustainable business orientation in which the archetype creates value from waste (Bocken et al., 2014). Several examples such as the mutualisation of assets and products (mutualized property and peer-to-peer renting), the extended producer responsibility (e.g. prolonged warranty or maintenance programs), as well as the reutilization and remanufacturing, suggest that PLE is part of the CE. In fact, PLE integrates within the three loops of the CE (Nussholz, 2017a). First, PLE fit in the "starting loop" through the improved design of products. Second, PLE fits in the "slowing loop" through maintenance, advice, consulting, temporary disposition through renting and lending and permanent disposition through disposition such as reselling, donations or swapping (Bakker et al., 2014). Finally, the PLE also fits in the "closing loop" since it involves remanufacturing and repair through take-back programs or reverse logistics (Nussholz, 2017b).

\section{Business models}

PLE can be observed and defined through certain characteristics of a business model. A business model represents a set of strategic decisions, which define how the company creates, transfers and captures value through its internal activities and their partnerships with key stakeholders such as suppliers and customers (Osterwalder, 2004; Osterwalder and Pigneur, 2010). A business model supports management by defining the positioning on the market of the company in comparison to competitors (Urbinati et al., 2017). Besides, a business model provides a simple and effective snapshot of the organizational structure and the process of corporate value creation (Wirtz et al., 2016). The business model further contributes to clearly define the way in which an organization transforms resources and capacities into economic value (Teece, 2010). Since it is a tool oriented toward practitioners and used within start-ups and companies, the standardized nature of the business model acts like a referent. 
The business model framework has allowed for meaningful analyses and thought-provoking discussions in the scientific literature on resource conservation, recycling and cleaner production (Bocken et al., 2014; Lüdeke-Freund and Dembek, 2017; Nussholz, 2017a, 2017 b; Urbinati et al., 2017; Whalen, 2017; Biloslavo et al. 2018). It is a tool, which is characterized by relevance, practical orientation, and scientific rigor. There exists in the literature business model taxonomies of sustainability (Bilosalvo et al., 2018) or the CE (Urbinati et al., 2017; Whalen, 2017), of which some contain diverse elements of PLE. However, to the best of the authors' knowledge, despite its value in mapping existing and potential PLE business models, there does not exist any taxonomy focused on PLE.

\section{Methodology for the development of a taxonomy}

\subsection{Summary of the proposed methodology}

This study aims to provide a systematic, inductive and quantitatively-oriented methodology for developing a PLEBM taxonomy. Taxonomies differ from both archetypes and typologies. A taxonomy develops classification schemes empirically (Hambrick, 1984). In other words, it is inductive in nature. In contrast, a typology develops categories of ideal corporate models considered as perfect or typical examples, called archetypes. In order to facilitate a systematic comparison of business models involved in PLE practices and to allow for the development of a taxonomy, this article proposes a rigorous methodology for developing a taxonomy, which encompasses a set of attributes for each dimension of business models.

In line with past topical literature (e.g. Hartmann et al., 2016), the article proposes to develop the taxonomy. First, a systematic literature review revealed relevant business model frameworks and their corresponding dimensions (Bocken et al., 2014). Second, we identify characteristics for each dimension according to the corpus of literature on ecological production,

green/ethical/responsible marketing, consumer behavior, supply chain management, collaborative economy and sustainability. Third, we apply cluster analysis to derive a taxonomy (Everitt et al., 2011). More concretely, a database is populated with a sample of business models of different 
organizations involved in PLE. The data collected about these organizations is qualitative in nature but is analyzed quantitatively using a classification algorithm and clustering dimensions from the PLEBM framework, in order to build the taxonomy inductively from the data.

\subsection{The conceptual framework of PLEBM}

There is no general rule on the number or the types of dimensions of a business model. For the purpose of this methodological procedure, we adopt the business model framework with its nine components (i.e., customer segmentation, customer relationship, key partners, cost structure, channels, key resources, offering, key activities, and revenue sources) (Osterwalder, 2004; Pigneur, 2010), because it is the most frequently used one in scholarly research (Urbinati et al., 2017). Accurate and reliable information on cost structure is generally hard to obtain due to its sensitive nature as confidential business intelligence. Unless researchers may enjoy privileged access to proprietary data, this type of dimension should be dropped from further elaboration of a conceptual framework of PLEBM. Similarly, key resources should be avoided because of its limited discriminatory power to form clusters. In fact, the main key resource in a PLE perspective is products, albeit new or second-hand, which would be relevant for all companies.

\subsubsection{Key activities}

Each organization performs different activities to produce and deliver its offering (Hartmann et al., 2016). For PLEBM, these activities involve processes, systems and procedures of PLEBM. According to the literature (e.g., Gaiardelli et al., 2014; Whalen, 2017; Ertz et al., 2017a, 2017b), there are five main PLE activities that may further split into more specific sub-activities (see Table 1). The improved design of a product can be associated with the "starting loop"; the prolonged use, consisting of both maintenance and access scheme, as well as the additional use of a product, consisting of redistribution, conflate with the "slowing loop"; and finally, the recovery matches the "closing loop" (Nussholz, 2017a, 2017b).

Table 1. Key activities

\begin{tabular}{l|l|l} 
Activities & Sub-activities & Definitions \\
\hline
\end{tabular}




\begin{tabular}{|c|c|c|}
\hline \multirow{2}{*}{$\begin{array}{l}\text { Improved } \\
\text { product } \\
\text { design } \\
\text { (starting loop) }\end{array}$} & $\begin{array}{l}\text { Improved product } \\
\text { and production } \\
\text { process }\end{array}$ & $\begin{array}{l}\text { Use of more durable parts, components, and production } \\
\text { processes }\end{array}$ \\
\hline & $\begin{array}{l}\text { Improved design } \\
\text { for repair }\end{array}$ & $\begin{array}{l}\text { Better design for repair, remanufacturing, refurbishing, and } \\
\text { reconditioning; Design for up-datable or up-gradable products } \\
\text { that do not have to be replaced in their entirety. }\end{array}$ \\
\hline \multirow{4}{*}{$\begin{array}{l}\text { Access } \\
\text { schemes } \\
\text { (slowing loop } \\
\text { - prolonged } \\
\text { use) }\end{array}$} & \multirow{4}{*}{$\begin{array}{l}\text { Access schemes } \\
\text { (use-oriented } \\
\text { service scape) }\end{array}$} & $\begin{array}{l}\text { Leasing: the lessee pays a regular fee for unlimited and } \\
\text { individual use of the product. }\end{array}$ \\
\hline & & $\begin{array}{l}\text { Renting: the customer uses the product individually for a } \\
\text { predetermined period. }\end{array}$ \\
\hline & & $\begin{array}{l}\text { Mutualising: the product is sequentially used by different } \\
\text { customers. }\end{array}$ \\
\hline & & $\begin{array}{l}\text { Pooling: the simultaneous use of a product by different } \\
\text { customers. }\end{array}$ \\
\hline \multirow[t]{4}{*}{$\begin{array}{l}\text { Maintenance } \\
\text { (slowing loop } \\
\text { - prolonged } \\
\quad \text { use) }\end{array}$} & $\begin{array}{l}\text { Maintenance } \\
\text { (product-oriented } \\
\text { service scape) }\end{array}$ & $\begin{array}{l}\text { Maintenance contracts: involve (extended) warranty, spare parts } \\
\text { and consumables delivery, inspection and diagnosis, } \\
\text { updates/upgrades, cleaning/safe-keeping, and product } \\
\text { installation / start-up / commissioning. }\end{array}$ \\
\hline & $\begin{array}{l}\text { Advice (product- } \\
\text { oriented service } \\
\text { scape) }\end{array}$ & $\begin{array}{l}\text { Advice contracts: through help desks, the provider dispenses } \\
\text { information and assistance to customers regarding the } \\
\text { management of product use, maintenance and repair (in case of } \\
\text { self-repair) via phone, email, and internet services, allowing } \\
\text { direct access to the supplier database. }\end{array}$ \\
\hline & $\begin{array}{l}\text { Training (product- } \\
\text { oriented service } \\
\text { scape) }\end{array}$ & $\begin{array}{l}\text { Training contracts: the provider offers training services to } \\
\text { support the client while defining how to use a product and } \\
\text { obtain best performance, improving the product efficiency } \\
\text { during use while assuring the safety and/or improving the } \\
\text { business. }\end{array}$ \\
\hline & $\begin{array}{l}\text { Consultancy } \\
\text { (product-oriented } \\
\text { service scape) }\end{array}$ & $\begin{array}{l}\text { Consultancy contracts: The provider offers consulting services } \\
\text { to the customer regarding product development and use, as well } \\
\text { as on business improvements. }\end{array}$ \\
\hline \multirow{4}{*}{$\begin{array}{l}\text { Access } \\
\text { schemes } \\
\text { (slowing loop } \\
\text { - prolonged } \\
\text { use) }\end{array}$} & \multirow{4}{*}{$\begin{array}{l}\text { Access schemes } \\
\text { (use-oriented } \\
\text { service scape) }\end{array}$} & $\begin{array}{l}\text { Leasing: The lessee pays a regular fee for unlimited and } \\
\text { individual use of the product. }\end{array}$ \\
\hline & & $\begin{array}{l}\text { Renting: the customer uses the product individually for a } \\
\text { predetermined period. }\end{array}$ \\
\hline & & $\begin{array}{l}\text { Mutualising: The product is sequentially used by different } \\
\text { customers. }\end{array}$ \\
\hline & & $\begin{array}{l}\text { Pooling: The simultaneous use of a product by different } \\
\text { customers. }\end{array}$ \\
\hline \multirow{3}{*}{$\begin{array}{c}\text { Redistribution } \\
\text { (slowing loop } \\
\text { - additional } \\
\text { use) }\end{array}$} & Donation & $\begin{array}{l}\text { Free passing of goods from one consumes who does not use it } \\
\text { anymore to another consumer who needs it. }\end{array}$ \\
\hline & Swapping & $\begin{array}{l}\text { Direct exchange of goods where no money or equivalent } \\
\text { medium is involved. Goods may also be exchanged for services } \\
\text { and services for goods. }\end{array}$ \\
\hline & $\begin{array}{l}\text { Secondhand } \\
\text { marketplace }\end{array}$ & $\begin{array}{l}\text { Exchange between two parties involving the transfer of a pre- } \\
\text { owned good in exchange for an amount of money considered } \\
\text { equivalent to it. }\end{array}$ \\
\hline $\begin{array}{l}\text { Recovery } \\
\text { (closing loop) }\end{array}$ & Product repair & $\begin{array}{l}\text { Repair: A provider offers repair services that may be performed } \\
\text { on- or off-site, directly or remotely, programmed or available } \\
24 / 7 \text { for emergencies. }\end{array}$ \\
\hline
\end{tabular}




\begin{tabular}{|l|l|l|}
\hline & $\begin{array}{l}\text { Preventive reparation: reparation programs that are defined by a } \\
\text { contract may be proposed in standard, customised or special } \\
\text { formats. }\end{array}$ \\
\cline { 2 - 3 } & $\begin{array}{l}\text { Full reparation contract: A provider is completely responsible } \\
\text { for the product performance. These solutions are nearly always } \\
\text { provided through a package. }\end{array}$ \\
\cline { 2 - 3 } $\begin{array}{l}\text { Remanufacturing / } \\
\text { refurbishing / } \\
\text { repackaging / } \\
\text { reconditioning }\end{array}$ & $\begin{array}{l}\text { The provider remanufactures, refurbishes or reconditions } \\
\text { existing products typically sourced from reverse logistics } \\
\text { systems, inverse supply chain, take back schemes, trade-in } \\
\text { programs, buy-back offers, or commercial returns. The provider } \\
\text { offers a like-new product, often with a like-new warranty and a } \\
\text { new serial number starting from an old product that has been } \\
\text { completely or partially disassembled and rebuilt up to include all } \\
\text { product updates. }\end{array}$ \\
\hline
\end{tabular}

\subsubsection{Key partners}

Key partners refer to the suppliers of the product (Whalen and Nussholz, 2016). This is a central dimension in the business model literature. In the field of the $\mathrm{CE}$, most studies involving PLE, are often designed and executed from a managerial viewpoint (e.g. Bocken et al., 2014; Bakker et al., 2014; Bocken et al., 2016; Bocken and Short, 2016; Whalen, 2017). Yet, this venerable orientation, overlooks consumers' involvement and perspective despite the rapidly increasing exchange schemes involving consumers in the collaborative economy (Belk, 2014; Schor and Fitzmaurice, 2015; Sundararajan, 2016; Martin, 2016; Zervas et al., 2017; Ertz et al., 2018); or, in product multiple lives practices (Ertz et al., 2017a, 2017b); or in lateral exchange markets (Perren and Kozinets, 2018). We propose a holistic consideration of consumers, which we shall call "peers", as potential partners supplying products to other organizations or between themselves. Consequently, as shown in Table 2, key partners are organizations and "peers" (consumers).

Table 2. Key partners

\begin{tabular}{|l|l|}
\hline Partners & Definitions \\
\hline Peers & $\begin{array}{l}\text { Individuals that are representative of themselves but not of a given for profit } \\
\text { or not for profit organization. }\end{array}$ \\
\hline Organizations & Moral entities that could be either for profit or not for profit. \\
\hline
\end{tabular}

\subsubsection{Channels}


Channels correspond to the conduits, which enable the transfer of the product (Whalen, 2017). Drawing on past research on conventional business models (e.g., Hartmann et al., 2016), stores, direct and digital channels are key alternatives. Yet, digital channels may be either informational/interactive, providing mere information, or transactional, allowing exchanges to take place (Karray and Sigué, 2018). Furthermore, in a context of PLE, additional channels need to be considered such as mail/transportation for take-back or reverse logistics programme (Zarbakhshnia et al., 2019). Besides, many business models in the collaborative economy rely heavily on peers to conduct exchanges, called peers touchpoints. In contrast, some access or redistribution systems rely not on peers but on free-floating touchpoints such as car (e.g., Car2Go, Zipcar) or bike fleets (e.g., Bixi) (Lamberton and Rose, 2012; Bardhi and Eckhardt, 2012), collection boxes, etc. Table 3 provides a summary of the major channels of relevance for PLE.

Table 3. Channels

\begin{tabular}{|l|l|}
\hline Channels & Definitions \\
\hline Stores & $\begin{array}{l}\text { Physical facilities that concentrate distributed or collected products at a central } \\
\text { hub, such as retailers' premises, plants, facilities, secondhand stores, donation } \\
\text { centers. }\end{array}$ \\
\hline Fixed touchpoints & $\begin{array}{l}\text { Decentralized points of distribution or collection of products, such as } \\
\text { decentralized fleets of cars or bikes, open libraries, or collection boxes. }\end{array}$ \\
\hline Peers touchpoints & Peers and their premises such as house, garage, attic, yard, or land. \\
\hline Mail / transportation & $\begin{array}{l}\text { Systems that enable the physical flow of products such as postal services, } \\
\text { express delivery services, and more broadly transportation systems by land, } \\
\text { air, or water. }\end{array}$ \\
\hline Direct & $\begin{array}{l}\text { Employees or providers in direct contact with the customers and the product } \\
\text { for the performance of the product lifetime extension practice, such as sales } \\
\text { personnel, technicians or consultants. }\end{array}$ \\
\hline $\begin{array}{l}\text { Digital interactive } \\
\text { platform }\end{array}$ & $\begin{array}{l}\text { Technological mediation such as a web platform or a mobile application, } \\
\text { which provides information or live support on the extension of product } \\
\text { lifetime. }\end{array}$ \\
\hline $\begin{array}{l}\text { Digital transactional } \\
\text { platform }\end{array}$ & $\begin{array}{l}\text { Technological mediation that provides the opportunity to conduct or schedule } \\
\text { the exchange of the product whose lifetime is to be extended. }\end{array}$ \\
\hline
\end{tabular}

\subsubsection{Customer segmentation}

Organizations tend to target specific customers. The most frequent classification distinguishes between companies (B2B) and individual consumers (B2C) (Hartmann et al., 2016). In the case of PLE, since we acknowledged that consumers or "peers" are relevant suppliers of used, or at least pre-owned, products, we will need to integrate their involvement at two levels. 
The first level refers to collaborative exchange which involves a mediator to which the product is being sourced and who then subsequently resells, recommerces, refurbishes, repackages reconditions or remanufactures the product by himself. This we will call " $\mathrm{C} 2 \mathrm{~B}$ " and it conflates with B2C. Additionally, the digital economy also enables either direct exchanges between peers themselves through a facilitating intermediary (e.g. application, website) or direct exchanges without the intervention of any intermediary (e.g. garage sales, flea markets) (Ertz et al., 2018; Perren and Kozinets, 2018). Therefore, as shown in Table 4, the three characteristics of this dimension are $\mathrm{B} 2 \mathrm{~B}, \mathrm{~B} 2 \mathrm{C} / \mathrm{C} 2 \mathrm{~B}$ and $\mathrm{C} 2 \mathrm{C}$.

Table 4. Customer segmentation

\begin{tabular}{|l|l|}
\hline Segmentation & Definitions \\
\hline B2B & A company A provides a product directly to another company B. \\
\hline C2B/B2C & $\begin{array}{l}\text { A consumer A provides a product to a mediating company who may then } \\
\text { provide the product to consumer B }\end{array}$ \\
\hline C2C & A consumer A provides a product directly to another consumer B \\
\hline
\end{tabular}

\subsubsection{Customer relationship}

This dimension refers to the nature of the interaction between organizations where individuals are involved in PLE (Palmer, 2007). The literature identifies two major types of interactions, namely transactional and relational (Liu et al., 2009; Hartmann et al., 2016). As depicted in Table 5, transactional relationships only require relatively impersonal interaction, only when a good is being exchanged (Dekker et al., 2019), whereas relational relationships involve more frequent and personalized interactions such as through training or maintenance services (Naudé and Sutton-Brady, 2019).

Table 5. Customer relationship

\begin{tabular}{|l|l|}
\hline Relationship & \\
\hline Transactional & $\begin{array}{l}\text { Interactions are impersonal and occur only whenever a good is being } \\
\text { exchanged or a product lifetime extension service is being performed. }\end{array}$ \\
\hline Relational & $\begin{array}{l}\text { Interactions are personalized and occur frequently before, during or after a } \\
\text { product is being exchanged or before, during or after a product lifetimes } \\
\text { extension service is being rendered. }\end{array}$ \\
\hline
\end{tabular}

\subsubsection{Offering}


The offer of products, also called value proposition, is the central dimension of all the business model conceptual frameworks (Osterwalder, 2004; Hartmann et al., 2016). According to Nussholz (2017a), the offer of an organization using PLE can be divided into two categories: principal and secondary. As shown in Table 6, whenever the offer is of principal nature in the organization, the model of the business is conceived to explicitly and proactively to allow PLE. In the secondary offer type, PLE is a by-product of organizational activities but not its main objective (Nußholz, 2018). In other words, although the organization does not explicitly structure its business model with PLE, the latter is an unintended consequence of the firm's activities.

Table 6. Offering

\begin{tabular}{|l|l|}
\hline Offering & The business model is conceived to deliberately extend product lifetimes \\
\hline Principal & $\begin{array}{l}\text { The business model is not conceived to deliberately extend product lifetimes } \\
\text { but does implement casual product lifetime extension processes, systems and } \\
\text { strategies as an addendum to existing core business processes; or provokes } \\
\text { product lifetimes extension as an unintended by-product of its core business } \\
\text { model }\end{array}$ \\
\hline
\end{tabular}

\subsubsection{Revenue model}

This dimension defines the sources of revenue that the organization derives from its activities. Past research (Osterwalder, 2004; Osterwalder and Pigneur, 2010) emphasized seven different sources of revenue. Again, in the specific context of PLE, it was decided to add donations / social financing and advertising because some digital $\mathrm{C} 2 \mathrm{C}$ platforms enable to collect money through such means (Perren and Kozinets, 2018). The characteristics of this dimension are shown in Table 7.

Table 7. Revenue model

\begin{tabular}{|l|l|}
\hline Revenue stream & Definitions \\
\hline Asset sale & Exchanging the ownership of a product or service for money. \\
\hline Asset renting & Temporarily granting the exclusive usage right of an asset. \\
\hline licensing & $\begin{array}{l}\text { Granting permission to use protected intellectual property, such as a patent } \\
\text { in exchange for a fee. }\end{array}$ \\
\hline Usage fee & Charged per use of a particular service. \\
\hline Subscription fee & Charged for the use of the service. \\
\hline Brokerage fee & Charged for an intermediate service. \\
\hline
\end{tabular}




\begin{tabular}{|l|l|}
\hline Advertising & Charged for the display of advertisements. \\
\hline Donation/crowdfunding & Money donated for no specific product or service in compensation. \\
\hline
\end{tabular}

The aggregation of the abovementioned seven dimensions and their corresponding thirty characteristics leads to the development of the conceptual framework of PLEBM presented in

Figure 1. This projection is used to describe the business model of organizations under study in a systematic and comprehensive manner.

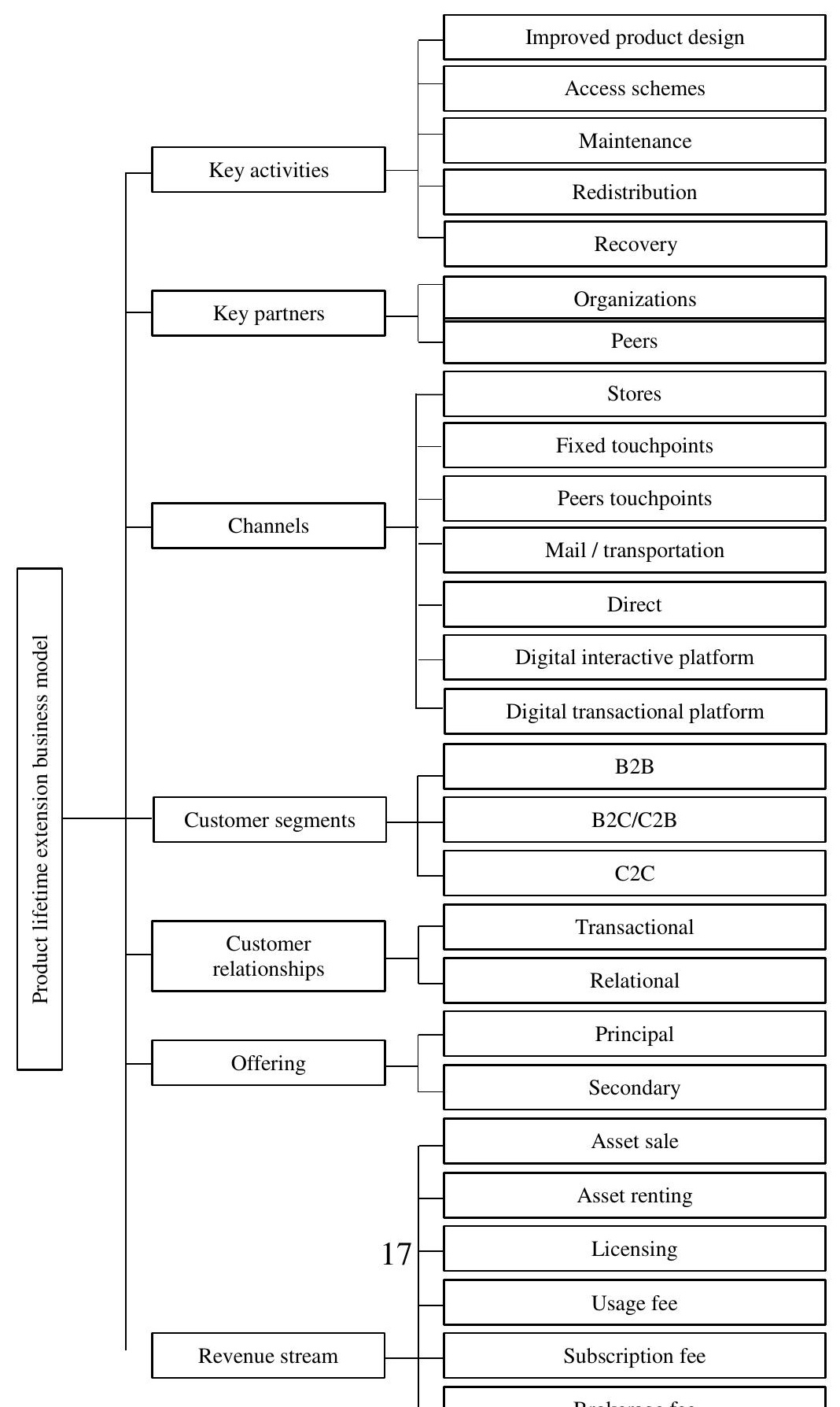


Figure 1. The Conceptual framework of PLEBM

\subsection{Step 1: Sampling}

The proposed methodology is focused on companies extending the lifetime of products through PLE activities. The sample of organizations from which to inductively derive the taxonomy should preferably be drawn from scientific publications on domains related to PLE such as the functional economy (product-service system) (Gaiardelli et al., 2014), the collaborative economy (Sundararajan, 2016), and lateral exchange systems (Perren and Kozinets, 2018), remanufacturing and repair (Whalen, 2017), or product multiple lives practices (Ertz et al., 2017a, 2017b). Well-known and relevant consultant publications (PwC, 2015; The Ellen MacArthur Foundation, 2015; Owyang, 2016) may also be considered. Furthermore, relevant refereed book chapters as well as refereed conference proceedings, may also be considered as sources for the sampling of organizations meant to populate the database.

\subsection{Step 2: Data collection}

The information pertaining to each organization listed in the database may be most efficiently found on the Internet but other secondary or even primary sources can be used. The literature emphasized that such secondary information is sufficient to describe business models (Teece, 2010). The systematic approach entailed in using a standardized canvass for collecting organizational data also ensures descriptive validity as well as reproducibility (Tashakkori and Teddlie, 2002).

\subsection{Step 3: Coding}


The next step is coding the organizations along the variables of the PLEBM (see Figure 1). Some of the ambiguous business model dimensions require judgement and are prone to coding errors (Cooper, 1988). Researchers should thus seek to minimize such errors and we offer next a few recommendations to reduce coding error. First, the characteristics of the framework should be clearly defined to the coder(s) before the start of the coding process to minimize potential mistakes (Cooper, 1988). Second, the coding should be binary, that is, a "1" is assigned if the organization exhibits a given characteristic (e.g. B2C customer segmentation) and a " 0 " is assigned if it doesn't (Hartmann et al., 2016). In fact, the preference for binary coding instead of multicategorical coding enables to take into account co-absences of features (i.e., neither of two business models have a particular feature) which are included in most distance measure techniques and overall clustering algorithms (Everitt et al., 2011). For example, the Euclidean distance includes both positive and negative matches (Choi et al., 2010), and requires therefore that matches and mismatches be reported explicitly. Third, in order to reduce the inherent bias in the interpretation of qualitative data, it is advisable to use a minimum of two independent coders, more coders will improve reliability and validity of the coding process. It might be of interest to confront the viewpoints of a coder involved in the study and another coder who is not involved in the study, or even perhaps who is not specialized in the domain under study (Hartmann et al., 2016). Finally, the coders should meet with a judge who should be involved in the study to resolve any disagreements (Fastoso and Whitelock, 2010). In line with Hartmann et al. (2016), disagreements between coders should be resolved by investigating the context of a particular statement.

\subsection{Step 4: Clustering analysis}

In line with the literature (Ketchen and Shook, 1996; Mooi and Sarstedt, 2011; Hartmann et al., 2016), a four-step process should be adopted in building the taxonomy: 1) selection of dimension(s); 2) selection of clustering algorithm and similarity measurement method; 3) selection of the number of clusters; and 4) validation and interpretation of the results. 
Selection of dimension(s). Researchers should select the dimensions as well as their variables to determine the belonging of the organization to a specific cluster. The choice should be based on two main considerations. Most importantly, the dimensions should be of great relevance (Milligan, 1996). The second consideration relates to the number of dimensions chosen for the clustering analysis, which is limited by the sample size (Mooi and Sarstedt, 2011). Hartmann et al. (2016) recommend sample size of at least $2^{\mathrm{m}}$, where $m$ corresponds to the number of clustering variables (see also Mooi and Sarstedt, 2011). For example, should a sample be composed of 150 organizations, the use of seven dimensions seems appropriate $\left(2^{7}=128\right)$. The choice of the appropriate clustering dimensions and variables lies at the crux of the clustering process and should be done carefully. The choice can be based on a multiplicity of factors but most importantly, the classification should answer the research questions. Although the use of two variables may be preferable for mapping the resulting clusters in a two-dimensional space, additional variables could also be considered, resulting in a richer but more complex multidimensional modelling (Tufféry, 2011). For example, both key activities and revenue stream could be used as clustering dimensions. The five remaining dimensions (channels, customer segmentation, customer relationship, and revenue sources) will then be used to describe the clusters.

Selection of clustering algorithm. Clustering is an unsupervised machine learning approach. Since the clustering data is binary in nature (i.e., 0 or 1 ), the most appropriate clustering method is a $k$-medoïds analysis using the partitioning around medoïds algorithm that can be found in the $R$ software. The $k$-medoïds algorithm groups $n$ objects into $k$ clusters by minimizing the sum of dissimilarity between each object, $p$, and its corresponding representative object, $o_{i}$ (medoïd), for all objects in cluster $C_{i}$. Other types of data, such as nominal, ordinal, interval or ratio variables may call for different types of clustering techniques. Both interval/ratio and nominal data, and big data in general, best suit the $K$-means clustering algorithm, whereas agglomerative hierarchical clustering is preferable for smaller datasets and ratio data (Hair et al., 2006). In hierarchical 
clustering the decision to merge two clusters is based on the closeness of the clusters, which may be measured by either Euclidean distance, or Squared Euclidean distance, or Manhattan distance, or Maximum distance, or Mahalanobis distance. K means clustering, in contrast, runs iteratively to find an optimum configuration. However, this algorithm requires prior knowledge of $\mathrm{K}$, that is, the number of clusters you want to divide your data into. This is typically hard to assess in an exploratory exercise such as that of building a taxonomy. Therefore, unless the researcher has prior knowledge of the dataset, or handle big data, it is preferable to use hierarchical clustering.

Selection of the number of clusters. The resulting number of clusters can be determined by using several procedures. First a rule of thumb suggests a total number of clusters that is equal to $\sqrt{\frac{n}{2}}$ (Han et al., 2012). For example, with $\mathrm{n}=150$, seven or eight clusters could be retained. Second, the elbow method can be used. A hierarchical clustering should be performed and then "the number of clusters is plotted against the agglomeration coefficient - the distance at which two cases or clusters are merged to form a new cluster" (Hartmann et al., 2016, p. 1392). Searching this plot for a distinctive break (“elbow”) signifies the appropriate number of clusters. This method is less precise than the previous one because there may appear "small elbows" confusing the overall interpretation. However, the elbow method has the advantage of determining the maximum number of clusters. Third, several statistical techniques determine the number of clusters (Pham et al., 2005), particularly in case of a K-means clustering procedure. These methods are usually based on quantitative indicators and are thus more precise. The most interesting method is called the silhouette coefficient (Rousseuw, 1987). According to Kaufman and Rousseeuw (1990), the closer the coefficient is to 1, the more the clustering analysis - and resulting number of clusters - is statistically valid. It may occur that the different coefficients resulting from different clustering configurations are relatively close to one another. This is frequent in the context of social sciences (Hambrick, 1984) and should be resolved by 
triangulation with other methods. The final number of clusters should be determined based on their theoretical and practical meaningfulness (Ketchen and Shook, 1996).

Validation and interpretation of the results. The ideal configuration should exhibit statistical, theoretical, and practical validity. First, statistical validity refers to the Silhouette coefficient in $k$ medoïds analysis. Theoretical validity refers to the extent to which the cluster configuration that are identified comprise a parsimonious number of clusters that do manifest PLE paradigms such as improved design, maintenance, redistribution, recovery, repair, or access schemes. Finally, practical validity, refers to the extent to which the results are meaningful and useful for practitioners. This means that practitioners may easily classify themselves as well as their competitors in either cluster of the resulting configuration. Normally, researchers should be able to do the same. This practical wisdom will be more easily reached when both statistical and theoretical soundness is ensured. Also, theoretical and practical meaningfulness should prevail over statistical validity. For example, a clustering configuration might yield high statistical validity but may entail questionable classifications (e.g. two radically different PLEBM such as Bixi and Amazon grouped in the same cluster). Logic, common sense and theoretical meaningfulness should thus always inform and prevail over strict statistical robustness. The final stage of validation and interpretation of the results should thus aim at reviewing in detail the composition of each cluster to ensure attainment of meaningful and practically relevant intracluster homogeneity and inter-cluster heterogeneity.

\section{Application of the proposed methodology}

In order to provide an empirical illustration of our proposed methodology, we conducted a case study by following the five-step methodology delineated previously.

\subsection{Step 1: Sampling}

We conducted a judgement sampling of observations drawn from scientific publications relevant to PLEBM, such as product-service system (Gaiardelli et al., 2014), collaborative economy 
(Sundararajan, 2016), lateral exchange market (Perren et Kozinets, 2018), repair and refurbishing (Whalen, 2017), or goods multiple lives practices (Ertz et al., 2017a, 2017b). We included as many organizations as possible to improve the generalization of the findings to the broader population of organizations engaged in PLEBM activities. The lack of selective choice of organizations within the listed publications has prevented researcher bias (Johnson, 1997) and has provided a representative sample for generalization purposes (Flyvbjerg, 2006).

\subsection{Step 2: Data collection}

From January $2^{\text {nd }}, 2018$, a sample of 150 organizations has been selected. Relevant information about organizations' characteristics along PLEBM dimensions has been identified on their publicly accessible website. Using public data guarantees descriptive validity and reproducibility of the research (Tashakkori et Teddlie, 2002).

\subsection{Step 3: Coding}

Data were analyzed manually and coded by two independent coders using the PLEBM conceptual framework (see Figure 1). The first coder was an author of this study, whereas the second was not specialized in the field studied and was not a participant in this research. Frame characteristics were clearly defined to both coders before coding to minimize potential errors (Cooper, 1988). Each characteristic was coded as a dummy variable $(0=$ No, $1=$ Yes $)$. There were 4,500 coded terms, of which $81 \%$ were identical for both coders. The remaining $19 \%$ was settled by the discussion of the two coders with a third person, another author, acting as a judge to resolve any disagreement (Fastoso and Whitelock, 2010). The coding process provided a dataset that allowed for subsequent classification.

\subsection{Step 4: Clustering analysis}

As suggested, in the proposed methodology, a four-step process was adopted to construct the taxonomy: 1) selection of dimension(s); 2) selection of clustering algorithm and similarity 
measurement method; 3) selection of the number of clusters; and 4) validation and interpretation of the results.

Selection of dimension. We started with selecting the clustering dimensions. Hartmann et al. (2016) recommend a sample size of at least $2^{\mathrm{m}}$, where $m$ is the number of clustering dimensions (see also Mooi et Sarstedt, 2011). Since our sample consisted of 150 organizations, the use of the seven dimensions of the PLEBM could be appropriate $\left(2^{7}=128\right)$. However, we chose to select only two clustering dimensions out of the seven of the PLEBM (see Figure 1), because a twodimensional cluster analysis is easier for modeling results in a figure, graph or picture (see Figure 2). The two variables that we chose are, key activities and revenue stream. Often PLE strategies are incorrectly considered to be unprofitable. Using both clustering dimensions will enable us to identify those revenue configurations that characterize organizations successfully engaged in PLE.

Selection of clustering algorithm. We selected the $k$-medoïds clustering method with the partitioning around medoïds (PAM) algorithm in the $R$ statistical software. The $k$-medoïds algorithm groups $n$ objects into $k$ clusters by minimizing the sum of dissimilarity between each object, $p$, and its corresponding representative object, $o_{i}$ (medoïd), for all the objects of group $C_{i}$ (Hartmann et al., 2016, p 1391).

Selection of the number of clusters. To determine the appropriate number of clusters for the analysis, we used the coefficient of Silhouette (Rousseeuw, 1987). According to Kaufman and Rousseeuw (1990), the closer the coefficient is to 1 , the more statistically accurate the analysis. The best configuration (statistical and conceptual) was a five-cluster configuration. Given the relatively large number of variables used compared to the size of our sample, the results of this configuration are de facto exploratory. The Silhouette coefficient of 0.427 remains very acceptable for studies in the social sciences (Hambrick, 1984). The results are shown in Table 8. 
Table 8. Secondary clustering of PLEBM (Key activities and revenue stream) according to their medoïds, their size and their Silhouette's coefficient

\begin{tabular}{|l|c|c|c|c|c|}
\hline Variables & Group V & Group W & Group X & Group Y & Group Z \\
\hline Key activities & & & & & \\
\hline Improved product design & 0 & 0 & 0 & 0 & 0 \\
\hline Access schemes & 0 & 1 & 0 & 1 & 1 \\
\hline Maintenance & 1 & 1 & 0 & 0 & 0 \\
\hline Redistribution & 0 & 1 & 1 & 0 & 0 \\
\hline Recovery & 1 & 1 & 0 & 0 & 0 \\
\hline Revenue stream & & & & & \\
\hline Asset sale & 1 & 1 & 1 & 0 & 0 \\
\hline Asset renting & 0 & 1 & 0 & 1 & 0 \\
\hline Licensing & 0 & 1 & 0 & 0 & 0 \\
\hline Usage fee & 1 & 1 & 0 & 0 & 0 \\
\hline Subscription fee & 0 & 0 & 0 & 1 & 0 \\
\hline Brokerage fee & 0 & 0 & 0 & 0 & 1 \\
\hline Size & 57 & 13 & 30 & 31 & 19 \\
\hline Silhouette & 0,379 & 0,474 & 0,401 & 0,343 & 0,718 \\
\hline
\end{tabular}

Validation and interpretation of the results. The final number of clusters has been validated by their theoretical and practical significance (Ketchen and Shook, 1996). The best configuration (statistical and conceptual) was five-cluster configuration. The sample characteristics of each group are shown in Table 9 and the clusters are represented graphically along their two clustering dimensions in Figure 2. The chi-square test between each variable and the five-cluster grouping were highly significant. Similarly, Cramer's $V$ values measuring the strength of the association between the describing variables and the cluster grouping were all above the desirable 0.3 level of association, suggesting moderately strong to very strong relationships. The Phi Coefficients showed exactly the same levels of association and levels of significance as Cramer's V. The distribution of the variables within each cluster is very diversified further suggesting relative intragroup homogeneity and intergroup heterogeneity. In other words, this five-cluster configuration provided the most significant results from a theoretical, practical and statistical point of view. 
Group V. Group V is the largest one (38\% of the sample), and encompasses organizations that are mainly active in maintenance, recovery (including remanufacturing, refurbishing, reconditioning and repair), and to a lesser extent, improved design. The bulk of their revenues thus mainly accrues from the selling of recovered and repaired products (i.e., asset sale), or from the provision of maintenance services (i.e., usage fee). This cluster groups together various B2B manufacturers such as ABB, Cisco, IBM, or Xerox, that are known for offering service level agreements (maintenance) to their clients while also offering them take-back, reverse logistics schemes (recovery/repair).

Group W. Organizations in this cluster use the broadest array of PLE activities thus also related to the vastest range of income streams. The companies within this group are mainly car manufacturers (e.g. Toyota, Audi, BMW, Renault-Nissan, Volkswagen), which explain that they are the only one involved in licensing because car manufacturers typically resell or rent cars through franchisees. Otherwise, their earn revenues from asset sales through the reselling of cars and parts. Usage fees refer to the various maintenance and reparation activities that are typically done on a regular basis for capital-intensive products such as cars. Yet, many manufacturers also offer daily, weekly, monthly or yearly car renting/leasing plans issuing them revenues from asset renting or subscription fees. offer car renting and leasing solutions which generate revenues doing business in B2C and B2B. Similarly to Group V, organizations in this group seem to be as much transactionally- as relationally-oriented, do not tend to be facilitators of $\mathrm{C} 2 \mathrm{C}$ exchanges, and hold their PLE activities as very peripheral to their core business of selling new products (for Group W, cars).

Group X. This cluster combines redistribution and product reselling, as well as improved design and access scheme, but to a much lesser extent. Since this cluster comprises many peer-topeer marketplaces such as Kijiji, LesPAC or Craigslist, revenues from both advertising and brokerage fees are relatively important. Several of these organizations generate profits by adding 
banner ads on their digital platforms and taking a fee on each $\mathrm{C} 2 \mathrm{C}$ transaction. Compared to the other clusters, mail and transportation is the most important in Group X.

Group Y. Group Y is specialized in access schemes, either through asset renting (77.40\%) or subscription (74.20\%) (e.g. Bixi, Communauto, Zipcar) in the B2C segment (87.1\%). These correspond to marketer-managed access systems (Lamberton and Rose, 2012; Bardhi and Eckhardt, 2012).

Group Z. Lastly, Group Z organizations are mostly involved in access schemes. Yet, this group is the most active in the $\mathrm{C} 2 \mathrm{C}$ segment by allowing the formation of consumer marketplaces. Typical examples include, Boasetter, Peerby, or KitSplit. These organizations thus provide a digital platform for consumers to rent/lease/lend products among each other. Brokerage fees are thus highest in this group. The involvement of peers as key partners is also highest in this group and the relationships are comparatively more relational in this group than in $\mathrm{X}$ or $\mathrm{Y}$, because peers often need to meet in-person to conduct exchanges. 
Table 9. Sample characteristics

\begin{tabular}{|c|c|c|c|c|c|c|c|c|c|c|}
\hline \multirow[t]{2}{*}{ Variables } & \multirow[t]{2}{*}{ Group V } & \multirow{2}{*}{$\begin{array}{l}\text { Group } \\
\text { W }\end{array}$} & \multirow{2}{*}{$\begin{array}{l}\text { Group } \\
\mathbf{X}\end{array}$} & \multirow{2}{*}{$\begin{array}{l}\text { Group } \\
\mathbf{Y}\end{array}$} & \multirow{2}{*}{$\begin{array}{l}\text { Group } \\
\mathbf{Z}\end{array}$} & \multirow{2}{*}{$\begin{array}{l}\text { Total } \\
(\mathrm{n} \\
150)\end{array}=$} & \multicolumn{3}{|c|}{ Chi-square test } & \multirow{2}{*}{$\begin{array}{c}\text { Cramer's } \\
\text { V }\end{array}$} \\
\hline & & & & & & & $\chi^{2}$ & $d . f$. & $\begin{array}{c}p- \\
\text { value }\end{array}$ & \\
\hline \multicolumn{11}{|l|}{ Key activities } \\
\hline Improved product design & $28.1 \%$ & $0.0 \%$ & $13.3 \%$ & $3.2 \%$ & $0.0 \%$ & $14.0 \%$ & 17.58 & 4 & 0.001 & $0.342 * *$ \\
\hline Access schemes & $5.3 \%$ & $61.5 \%$ & $10.0 \%$ & $96.8 \%$ & $100.0 \%$ & $42.0 \%$ & 110.65 & 4 & 0.000 & $0.859 * * *$ \\
\hline Maintenance & $96.5 \%$ & $100.0 \%$ & $0.0 \%$ & $9.7 \%$ & $0.0 \%$ & $47.3 \%$ & 131.39 & 4 & 0.000 & $0.936 * * *$ \\
\hline Redistribution & $5.3 \%$ & $92.3 \%$ & $86.7 \%$ & $9.7 \%$ & $0.0 \%$ & $29.3 \%$ & 102.04 & 4 & 0.000 & $0.825 * * *$ \\
\hline Recovery & $78.9 \%$ & $100.0 \%$ & $0.0 \%$ & $0.0 \%$ & $0.0 \%$ & $38.7 \%$ & 110.05 & 4 & 0.000 & $0.857 * * *$ \\
\hline \multicolumn{11}{|l|}{ Revenue stream } \\
\hline Asset sale & $64.9 \%$ & $84.6 \%$ & $63.3 \%$ & $3.2 \%$ & $0.0 \%$ & $45.3 \%$ & 58.77 & 4 & 0.000 & $0.626^{* * *}$ \\
\hline Asset renting & $7.0 \%$ & $92.3 \%$ & $3.3 \%$ & $77.4 \%$ & $21.1 \%$ & $30.0 \%$ & 82.45 & 4 & 0.000 & $0.741 * * *$ \\
\hline Licensing & $8.8 \%$ & $69.2 \%$ & $0.0 \%$ & $3.2 \%$ & $0.0 \%$ & $10.0 \%$ & 57.80 & 4 & 0.000 & $0.621 * * *$ \\
\hline Usage fee & $73.7 \%$ & $76.9 \%$ & $20.0 \%$ & $29.0 \%$ & $0.0 \%$ & $44.7 \%$ & 50.68 & 4 & 0.000 & $0.581 * * *$ \\
\hline Subscription fee & $26.3 \%$ & $38.5 \%$ & $13.3 \%$ & $74.2 \%$ & $10.5 \%$ & $32.7 \%$ & 34.88 & 4 & 0.000 & $0.482 * * *$ \\
\hline Brokerage fee & $0.0 \%$ & $0.0 \%$ & $26.7 \%$ & $0.0 \%$ & $89.5 \%$ & $16.7 \%$ & 94.88 & 4 & 0.000 & $0.795 * * *$ \\
\hline Advertising & $1.8 \%$ & $0.0 \%$ & $23.3 \%$ & $3.2 \%$ & $0.0 \%$ & $6.0 \%$ & 20.27 & 4 & 0.000 & $0.368 * * *$ \\
\hline \multicolumn{11}{|l|}{ Key partners } \\
\hline Organizations & $100.0 \%$ & $100.0 \%$ & $56.7 \%$ & $93.5 \%$ & $15.8 \%$ & $79.3 \%$ & 78.25 & 4 & 0.000 & $0.722 * * *$ \\
\hline Peers & $19.3 \%$ & $23.1 \%$ & $76.7 \%$ & $6.5 \%$ & $89.5 \%$ & $37.3 \%$ & 63.61 & 4 & 0.000 & $0.651 * * *$ \\
\hline \multicolumn{11}{|l|}{ Channels } \\
\hline Stores & $59.6 \%$ & $100.0 \%$ & $33.3 \%$ & $35.5 \%$ & $15.8 \%$ & $47.3 \%$ & 29.62 & 4 & 0.000 & $0.444 * * *$ \\
\hline Fixed touchpoints & $0.0 \%$ & $0.0 \%$ & $0.0 \%$ & $32.3 \%$ & $0.0 \%$ & $6.7 \%$ & 41.13 & 4 & 0.000 & $0.524 * * *$ \\
\hline Peers touchpoints & $0.0 \%$ & $0.0 \%$ & $33.3 \%$ & $9.7 \%$ & $84.2 \%$ & $19.3 \%$ & 73.68 & 4 & 0.000 & $0.701 * * *$ \\
\hline Mail/Transportation & $29.8 \%$ & $7.7 \%$ & $56.7 \%$ & $19.4 \%$ & $5.3 \%$ & $28.0 \%$ & 21.00 & 4 & 0.000 & $0.374 * * *$ \\
\hline Direct & $68.4 \%$ & $84.6 \%$ & $3.3 \%$ & $6.5 \%$ & $0.0 \%$ & $35.3 \%$ & 76.27 & 4 & 0.000 & $0.713 * * *$ \\
\hline Digital interactive platform & $35.1 \%$ & $76.9 \%$ & $23.3 \%$ & $16.1 \%$ & $10.5 \%$ & $29.3 \%$ & 21.48 & 4 & 0.000 & $0.378 * * *$ \\
\hline Digital transactional platform & $29.8 \%$ & $15.4 \%$ & $60.0 \%$ & $74.2 \%$ & $84.2 \%$ & $50.7 \%$ & 32.84 & 4 & 0.000 & $0.468 * * *$ \\
\hline \multicolumn{11}{|l|}{ Customer segments } \\
\hline B2B & $73.7 \%$ & $53.8 \%$ & $20.0 \%$ & $29.0 \%$ & $5.3 \%$ & $43.3 \%$ & 42.42 & 4 & 0.000 & $0.532 * * *$ \\
\hline $\mathrm{B} 2 \mathrm{C} / \mathrm{C} 2 \mathrm{~B}$ & $56.1 \%$ & $69.2 \%$ & $63.3 \%$ & $87.1 \%$ & $15.8 \%$ & $60.0 \%$ & 25.91 & 4 & 0.000 & $0.416 * * *$ \\
\hline
\end{tabular}




\begin{tabular}{|l|l|l|l|l|l|l|l|l|l|l|}
\hline C2C & $1.8 \%$ & $0.0 \%$ & $46.7 \%$ & $0.0 \%$ & $89.5 \%$ & $21.3 \%$ & 88.99 & 4 & 0.000 & $0.770^{* * *}$ \\
\hline Customer relationships & & & & & & & & & & \\
\hline Transactional & $75.4 \%$ & $76.9 \%$ & $100.0 \%$ & $100.0 \%$ & $100.0 \%$ & $88.7 \%$ & 21.94 & 4 & 0.000 & $0.382^{* * *}$ \\
\hline Relational & $75.4 \%$ & $76.9 \%$ & $6.7 \%$ & $9.7 \%$ & $5.3 \%$ & $39.3 \%$ & 72.92 & 4 & 0.000 & $0.697 * * *$ \\
\hline Offering & & & & & & & & & & \\
\hline Principal & $19.3 \%$ & $15.4 \%$ & $90.0 \%$ & $93.5 \%$ & $100.0 \%$ & $58.7 \%$ & 87.56 & 4 & 0.000 & $0.764 * * *$ \\
\hline Secondary & $80.7 \%$ & $84.6 \%$ & $10.0 \%$ & $6.5 \%$ & $0.0 \%$ & $41.3 \%$ & 87.56 & 4 & 0.000 & $0.764 * * *$ \\
\hline Size & 57 & 13 & 30 & 31 & 19 & 150 & & & & \\
\hline Silhouette & 0,379 & 0,474 & 0,401 & 0,343 & 0,718 & 0.427 & & & & \\
\hline
\end{tabular}

$* * * \mathrm{p}<0.001 ; * * \mathrm{p}<0.01, * \mathrm{p}<0.05$.

Note: The total across sub-categories are not mutually exclusive, and may thus not add up to $100.0 \%$ since business models may be characterized by multiple key activities, revenue streams, key partners, channels, customer segments simultaneously. Only offering is binary since the PLE is either principal or secondary to the organization's business but cannot be both simultaneously. 


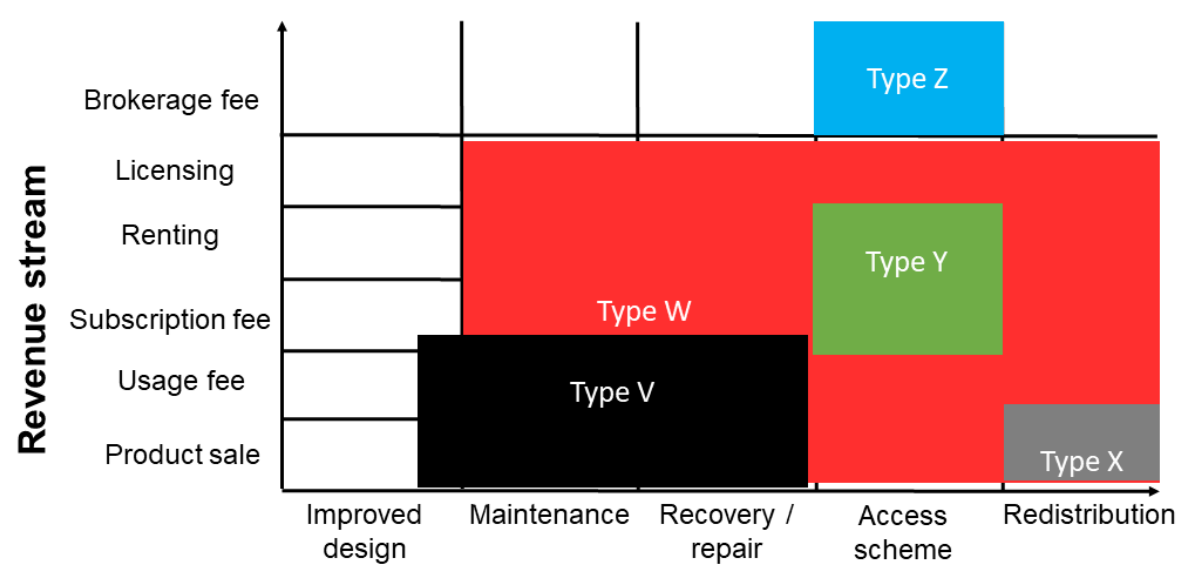

Key activities

Figure 2. Visual representation of the taxonomy

\section{Discussion}

This study applies a newly-proposed methodology to a sample of 150 organizations drawn from the literature and uses key activities and revenue stream as clustering dimensions, to reveal a five-cluster taxonomy of PLEBM, addressing therefore the first research question (i.e., How to imbue a taxonomy with quantitative rigor while retaining the explanatory potential for mapping new or existing PLEBM?). This classification sheds new light on the links between revenue streams and PLEBM. More precisely, a natural demarcation has emerged between traditional enterprises and those of the collaborative economy. In fact, both group $\mathrm{V}$ and $\mathrm{W}$ comprise flagships of traditional business involving large, multinational, capital-intensive corporations mainly involved in inter-organizational and consumer marketplaces. In contrast, groups $\mathrm{X}, \mathrm{Y}$, and $\mathrm{Z}$ embody the collaborative economy in that they are mainly digital, characterized by the confluence of redistribution and access schemes, and with a heavier involvement of peers (C2C) (Belk, 2014; Ertz et al., 2017c). Although stores remain an important channel, it appears that $\mathrm{X}, \mathrm{Y}$, and $\mathrm{Z}$ are omnichannel-prone by being present across virtually all channels, especially digitally transactional 
ones, to which all other online and offline channels may be connected in an integrated fashion (Adivar et al., 2019). The prevailing channels are digital transactional platforms not just digitally interactive. While mail and transportation are not new channels, fixed touchpoints such as freefloating car or bike fleets, donation boxes, or booksharing stations, or peer touchpoints, which are individuals' homes, garages, land, and assets are in fact new types of channels. PLE is principal to the offering of these clusters, yet relationships tend to be much more transactional further suggesting that commercially-oriented PLE platforms and applications are mostly utilitarian and do not allow the development of communities as underscored by Bardhi and Eckhardt (2012), or long-term ties like in traditional business models found in $\mathrm{V}$ or $\mathrm{W}$. By developing a rigorous and theory-informed methodology for the modeling and clustering of PLEBM taxonomy, using validity and reliability indicators, this study addresses the second research question (i.e., How to apply systematic and analytical business modelling for a credible representation of the variety of business configurations observed in the $\mathrm{CE}$ as well as developing them into a classification that is compelling, defendable and plausible?). Finally, by including the consumer as a key partner in the PLEBM framework, in addition to organizations, this study answers the third research question (i.e., How to relate the consumer to organizational PLE strategies?).

\section{Theoretical and managerial implications}

The current research contributes to the literature on the collaborative economy, in general, and PLE in particular in several ways. In a recent but influential study of 114 definitions of the CE, Kirchherr et al. (2017) highlighted that neither business models nor consumers are frequently being considered as enablers of the CE in general, and PLE in particular. Similarly, in an extensive review of the literature of the past two decades, Ghisellini et al. (2016) emphasized that despite the need to involve all actors of the society, in order to achieve the transition towards a $\mathrm{CE}$, there was yet little emphasis on consumers. They noted that the implementation of the $\mathrm{CE}$ worldwide still seems in the early stages, mainly focusing on recycle, instead of product reuse, 
hence PLE. While consumer behavior literature, anthropology and marketing have offered ample theoretical and empirical evidence to disprove the irrelevance of the consumer in the study of the $\mathrm{CE}$, few studies integrated both consumer and business models in the CE stream in general and in PLE in particular.

Focusing on PLE within the CE research stream, the current study overcomes deficiencies in the literature by offering a methodology to map and classify organizations according to the business model framework. The proposed methodology integrates consumer input as relevant and important in the supply of products, as organizations. The methodological advance offered in this study is therefore comprehensive, consistent and integrative of other disciplines in the social sciences as well as ecologically valid to map organizations enacting PLE.

For managers, this enables them to systematically map their own organization, competitors and other relevant stakeholders in a uniform way. The resulting taxonomies also enable them to identify business opportunities by easily identifying gaps or empty spots.

For both scholars and managers like, an important concern related to the methodological advance in PLE proposed in this study, is that researchers tend to apply methodologies like templates. Others still treat methodologies as formulas. In our case, this could consist in reproducing the exact same format of PLEBM as suggested in this article with little consideration for the dimensions and variables that need to be idiosyncratically added or removed from the business model framework, depending on the research context and objectives. We envision the approach proposed in this study as a "methodology" and not a "method". More specifically, we consider it as a "flexible orientation toward [...] inductive research that is open to innovation, rather than a "cookbook"' (Gioia et al., 2012, p. 26). In other words, new studies applying the PLEBM methodology may contain some sort of methodological innovation, which could go as far as to use a different framework of dimensions and variables for classification. When the approach is treated as a template or cookbook, this would not be feasible as it constrains these innovative possibilities. Another point of contention in using our approach as a template or 
cookbook is that it would impede the attainment of rigor and validity, which was the main intent of proposing this methodology in the first place. Hence, treating the proposed approach as a methodology rather than a method, cookbook or template will enable researchers a creative and innovative free space while rigorously demonstrating connections between theory and data.

\section{Limitations and research avenues}

The proposed model is especially relevant for exploratory purposes. While very appropriate for conducting formal mappings of the PLE business models, the proposed PLEBM framework potentially neglects dimensions that are less prominent in past literature. In that sense, the dynamic nature of business models was not explicitly reflected. It should be noted that business models in a novel domain such as PLE may be subject to change and innovation over time, ranging from incremental to disruptive. The proposed methodology is flexible enough to allow for changes in the underlying variables and characteristics used to define business models, as the remainder of the procedure remains unchanged.

\section{Conflict of interest}

The authors declare that they do not have any conflict of interest.

\section{Ethical approval}

This study does not contain any studies with human participants performed by any of the authors.

\section{References}

Adivar, B., Hüseyinoğlu, I.Ö.Y., \& Christopher, M. (2019). A quantitative performance management framework for assessing omnichannel retail supply chains. Journal of Retailing and Consumer Services, 48, 257-269.

Babbitt, C. W., Gaustad, G., Fisher, A., Chen, W. Q., \& Liu, G. (2018). Closing the loop on circular economy research: From theory to practice and back again. Resources, Conservation and Recycling, 135, 1-2.

Bakker, C., den Hollander, M.C., Van Hinte, E., \& Zijlstra, Y. (2014). Products that last: product Design for Circular Business Models ( $1^{\text {st }}$ ed.). Delft: TU Delft Library/Marcel den Hollander IDRC.

Bardhi, F., \& Eckhardt, G. M. (2012). Access-based consumption: The case of car sharing. Journal of consumer research, 39(4), 881-898.

Belk, R. (2014). You are what you can access: Sharing and collaborative consumption online. Journal of Business Research, 67(8), 1595-1600. 
Biloslavo, R., Bagnoli, C., \& Edgar, D. (2018). An eco-critical perspective on business models: The value triangle as an approach to closing the sustainability gap. Journal of Cleaner Production, 174, 746-762.

Bocken, N.M.P., \& Short, S.W. (2016). Towards a sufficiency-driven business model: Experiences and opportunities. Environmental Innovation and Societal Transitions, 18, 4161.

Bocken, N.M., de Pauw, I., Bakker, C., \& van der Grinten, B. (2016). Product design and business model strategies for a circular economy. Journal of Industrial and Production Engineering, 33(5), 308-320.

Bocken, N.M., Short, S.W., Rana, P., \& Evans, S. (2014). A literature and practice review to develop sustainable business model archetypes. Journal of Cleaner Production, 65, 42-56.

Chesbrough, H., \& Rosenbloom, R.S. (2002). The role of the business model in capturing value from innovation: evidence from Xerox Corporation's technology spin-off companies. Industrial and Corporate Change, 11(3), 529-555.

Choi, S.S., Cha, S.H., \& Tappert, C.C. (2010). A survey of binary similarity and distance measures. Journal of Systemics, Cybernetics and Informatics, 8(1), 43-48.

Cooper, H.M. (1988). Organizing knowledge syntheses: A taxonomy of literature reviews. Knowledge in Society, 1(1), 104.

Cooper, T. (2018). The Significance of Product. In T. Cooper (Ed.) Longer lasting products: alternatives to the throwaway society (pp. 3-38). Gower Publishing Limited: Farnham.

Cox, J., Griffith, S., Giorgi, S., \& King, G. (2013). Consumer understanding of product lifetimes. Resources, Conservation and Recycling, 79, 21-29.

Dekker, H., Donada, C., Mothe, C., \& Nogatchewsky, G. (2019). Boundary spanner relational behavior and inter-organizational control in supply chain relationships. Industrial Marketing Management, 77, 143-154.

Erevelles, S., Fukawa, N., \& Swayne, L. (2016). Big Data consumer analytics and the transformation of marketing. Journal of Business Research, 69(2), 897-904.

Ertz, M., Durif, F., \& Arcand, M. (2017a). Life after death? Study of goods multiple lives practices. Journal of Consumer Marketing, 34(2), 108-118.

Ertz, M., Durif, F., \& Arcand, M. (2017b). Towards Multilife Marketing: How Goods Multiple Lives Practices Create Value for Consumers. Journal of Promotion Management, 1-32.

Ertz, M., Durif, F., \& Arcand, M. (2018). Business at the fingertips of consumers: a scale for measuring resale motivations in online settings. The International Review of Retail, Distribution and Consumer Research, 28(1), 92-114.

Ertz, M., Durif, F., François-Lecompte, A., \& Boivin, C. (2018). Does "sharing” mean "socially responsible consuming"? Exploration of the relationship between collaborative consumption and socially responsible consumption. Journal of Consumer Marketing, 35(4), 392-402.

Ertz, M., Lecompte, A., \& Durif, F. (2017c). Dual roles of consumers: towards an insight into collaborative consumption motives. International Journal of Market Research, 59(6), 725748.

Everitt, B.S., Landau, S., Leese, M., \& Stahl, D. (2011). Hierarchical clustering. In Cluster Analysis (5th ed.) (pp.71-110).

Fastoso, F., \& Whitelock, J. (2010). Regionalization vs. globalization in advertising research: Insights from five decades of academic study. Journal of International Management, $16(1), 32-42$.

Flyvbjerg, B. (2006). Five misunderstandings about case-study research. Qualitative inquiry, 12(2), 219-245.

Gaiardelli, P., Resta, B., Martinez, V., Pinto, R., \& Albores, P. (2014). A classification model for product-service offerings. Journal of Cleaner Production, 66, 507-519. 
Ghisellini, P, Cialani, C, \& Ulgiati, S (2016). A review on circular economy: the expected transition to a balanced interplay of environmental and economic systems. Journal of Cleaner Production, Volume 114, pp. 11-32. https://doi.org/10.1016/j.jclepro.2015.09.007.

Gioia, D.A., Corley, K.G., \& Hamilton, A.L. (2013). Seeking qualitative rigor in inductive research: Notes on the Gioia methodology. Organizational Research Methods, 16(1), 1531.

Guba, E.G., \& Lincoln, Y.S. (1994). Competing paradigms in qualitative research. Handbook of qualitative research, 2(163-194), 105.

Hair, J.F., Black, W.C., Babin, B.J., Anderson, R.E., \& Tatham, R.L. (2006). Multivariate data analysis. Uppersaddle River, NJ: Pearson Prentice Hall.

Hambrick, D.C. (1984). Taxonomic approaches to studying strategy: Some conceptual and methodological issues. Journal of Management, 10(1), 27-41.

Han, J., Kamber, M., \& Pei, J. (2012). Data mining: concepts and techniques (the Morgan Kaufmann Series in data management systems). Waltham: Morgan Kaufmann Publishers.

Hartmann, P.M., Zaki, M., Feldmann, N., \& Neely, A. (2016). Capturing value from big data-a taxonomy of data-driven business models used by start-up firms. International Journal of Operations \& Production Management, 36(10), 1382-1406.

Hazen, B.T., Mollenkopf, D.A., \& Wang, Y. (2017). Remanufacturing for the circular economy: An examination of consumer switching behavior. Business Strategy and the Environment, 26(4), 451-464.

Heiskanen, E. (1996). Conditions for product life extension. National Consumer Research Centre Working Papers, 22, 1996.

Johnson, R.B. (1997). Examining the validity structure of qualitative research. Education, 118(2), 282.

Karray, S., \& Sigué, S.P. (2018). Informational and/or transactional websites: Strategic choices in a distribution channel. Electronic Commerce Research and Applications, 27, 11-22.

Kaufman, L.R., \& Rousseeuw, P.P.J (1990). Finding groups in data: An introduction to cluster analysis. Hoboken, NJ: John Wiley \& Sons Inc.

Ketchen, D.J., \& Shook, C.L. (1996). The application of cluster analysis in strategic management research: an analysis and critique. Strategic Management Journal, 441-458.

Khan, M.A., Mittal, S., West, S., \& Wuest, T. (2018). Review on upgradability-A product lifetime extension strategy in the context of product service systems. Journal of Cleaner Production, 204, 1154-1168.

Kirchherr, J., Reike, D., \& Hekkert, M. (2017). Conceptualizing the circular economy: An analysis of 114 definitions. Resources, Conservation and Recycling, 127, 221-232.

Lamberton, C. P., \& Rose, R. L. (2012). When is ours better than mine? A framework for understanding and altering participation in commercial sharing systems. Journal of Marketing, 76(4), 109-125.

Liu, Y., Luo, Y., \& Liu, T. (2009). Governing buyer-supplier relationships through transactional and relational mechanisms: Evidence from China. Journal of Operations Management, 27(4), 294-309.

Lüdeke-Freund, F., \& Dembek, K. (2017). Sustainable business model research and practice: Emerging field or passing fancy?. Journal of Cleaner Production, 168, 1668-1678.

Lüdeke-Freund, F., Carroux, S., Joyce, A., Massa, L., \& Breuer, H. (2018). The sustainable business model pattern taxonomy - 45 patterns to support sustainability-oriented business model innovation. Sustainable Production and Consumption, 15, 145-162.

Manninen, K., Koskela, S., Antikainen, R., Bocken, N., Dahlbo, H., \& Aminoff, A. (2018). Do circular economy business models capture intended environmental value propositions?.

Journal of Cleaner Production, 171, 413-422.

Martin, C.J. (2016). The sharing economy: A pathway to sustainability or a nightmarish form of neoliberal capitalism?. Ecological Economics, 121, 149-159. 
Matzler, K., Veider, V., \& Kathan, W. (2015). Adapting to the sharing economy. Cambridge: MIT Press.

Milligan, G.W. (1996). Clustering validation: results and implications for applied analyses. In P. Arabie, L.J. Hubert, and G. De Soete (Eds.), Clustering and classification (pp. 341-375). River Edge: World Scientific Publishing.

Mooi, E., \& Sarstedt, M. (2011). A concise guide to market research, chapter 9: "Cluster analysis”. Berlin: Springer-Verlag.

Muranko, Z., Andrews, D., Newton, E. J., Chaer, I., \& Proudman, P. (2018). The Pro-Circular Change Model (P-CCM): Proposing a framework facilitating behavioural change towards a Circular Economy. Resources, Conservation and Recycling, 135, 132-140.

Naudé, P., \& Sutton-Brady, C. (2019). Relationships and networks as examined in Industrial Marketing Management. Industrial Marketing Management,

Nussholz, J.L.K. (2017a). Circular business models: Defining a cconcept and framing an emerging research field. Sustainability, 9(1810), 1-16.

Nussholz, J.L.K. (2017b). Circular business model framework: Mapping value creation architectures along the product lifecycle. In: C.A. Bakker and R. Mugge (eds.), Proceedings of PLATE 2017, November 2017, Delft, the Netherlands, Delft University of Technology and IOS Press.

Nußholz, J.L. (2018). A circular business model mapping tool for creating value from prolonged product lifetime and closed material loops. Journal of Cleaner Production, 197, 185-194.

Osterwalder, A. (2004). The business model ontology: A proposition in a design science approach. Unpublished $\mathrm{PhD}$ thesis. Available at: https://s3.amazonaws.com/academia.edu.documents/30373644/thebusiness-modelontology.pdf?AWSAccessKeyId=AKIAIWOWYYGZ2Y53UL3A\&Expires=1526412245 \&Signature=NebomaYtqCSFVGrsBoY3Q6fosLA\%3D\&response-contentdisposition=inline \%3B\%20filename\%3DThe_Business_Model_Ontology_a_propositio.pd $\mathrm{f}$ (accessed 15-05-2018).

Osterwalder, A., \& Pigneur, Y. (2010). Business model generation: a handbook for visionaries, game changers, and challengers. John Wiley \& Sons.

Owyang, J. (2016). Collaborative economy honeycomb version 3.0. Available at: http://www.web-strategist.com/blog/2016/03/10/honeycomb-3-0-the-collaborativeeconomy-market-expansion-sxsw/ (accessed 09-10-2018).

Palmer, R. (2007). The transaction-relational continuum: conceptually elegant but empirically denied. Journal of Business \& Industrial Marketing, 22(7), 439-451.

Perren, R., \& Kozinets, R.V. (2018). Lateral Exchange Markets: How Social Platforms Operate in a Networked Economy. Journal of Marketing, 82(1), 20-36.

Pham, D.T.; Dimov, S.S.; Nguyen, C.D. (2005), "Selection of K in K-means clustering”, In

Popper, K. (1959/2002). The logic of scientific discovery. London: Routledge. Proceedings of the Institution of Mechanical Engineers, Part C: Journal of Mechanical

$\mathrm{PwC}$ (2015). The sharing economy. Available at: https://www.pwc.fr/fr/assets/files/pdf/2015/05/pwc_etude_sharing_economy.pdf (accessed 15-05-2018).

Rousseeuw, P.J. (1987). Silhouettes: a graphical aid to the interpretation and validation of cluster analysis. Journal of Computational and Applied Mathematics, 20, 53-65.

Schor, J.B., \& Fitzmaurice, C.J. (2015). Collaborating and connecting: the emergence of the sharing economy. In L. Reisch and J. Thogersen (Eds.), Handbook of research on sustainable consumption (pp. 410-425). Cheltenham, UK: Edward Elgar.

Sundararajan, A. (2016). The sharing economy: The end of employment and the rise of crowdbased capitalism. Cambridge: MIT Press.

Tashakkori, A., \& Teddlie, C. (2002). Tye past and future of Mixed Methods Research: From Data Triangulation to Mixed Models Designs. In M.M. Bergman (Ed.), Handbook of 
Mixed Methods in Social \& Behavorial Research. Thousand Oaks: Sage Publications (pp. 101-119). London: SAGE Publications.

Teece, D.J. (2010). Business models, business strategy and innovation. Long Range Planning, 43(2-3), 172-194.

The Ellen MacArthur Foundation (2017). Delivering the circular economy: a toolkit for policymakers.

Tufféry, S. (2011). Data mining and statistics for decision making ( $2^{\text {nd }}$ ed.). Chichester: John Wiley \& Sons.

Urbinati, A., Chiaroni, D., \& Chiesa, V. (2017). Towards a new taxonomy of circular economy business models. Journal of Cleaner Production, 168, 487-498.

Whalen, K. (2017). Classifying circular business models: A practice-based review. In: C.A. Bakker and R. Mugge (eds.), Proceedings of PLATE 2017, November 2017, Delft, the Netherlands, Delft University of Technology and IOS Press.

Whalen, K.A., Berlin, C., Ekberg, J., Barletta, I., \& Hammersberg, P. (2018). 'All they do is win': Lessons learned from use of a serious game for Circular Economy education. Resources, Conservation and Recycling, 135, 335-345.

Whalen, K., \& Nussholz, J. (2016). Building Extended Value Chains: Lessons from Swedish ICT Repair and Resale 'Gap Exploiters' for Original Equipment Manufacturers. In Electronics Goes Green 2016+.

Wirtz, B.W., Pistoia, A., Ullrich, S., \& Göttel, V. (2016). Business models: Origin, development and future research perspectives. Long Range Planning, 49(1), 36-54.

World Bank (2018). What a waste 2.0: A global snapshot of solid waste management to 2050. Available at: file:///C:/Users/Myriam/Downloads/9781464813290.pdf (accessed 09-102018).

Zarbakhshnia, N., Soleimani, H., Goh, M., \& Razavi, S. S. (2019). A novel multi-objective model for green forward and reverse logistics network design. Journal of Cleaner Production, 208, 1304-1316.

Zervas, G., Proserpio, D., \& Byers, J. W. (2017). The rise of the sharing economy: Estimating the impact of Airbnb on the hotel industry. Journal of Marketing Research, 54(5), 687-705. 